\title{
Digit Span Backward Subtest (WISC-V)
}

National Cancer Institute

\section{Source}

National Cancer Institute. Digit Span Backward Subtest (WISC-V). NCI Thesaurus. Code C120358.

A subtest of the Wechsler Intelligence Scale for Children, Fifth Edition. The subject is read a sequence of numbers and recalls the numbers in reverse order. 